\title{
The IRPA Young Generation Network: Activity Report from the Middle of 2018 to the Beginning of 2021
}

\author{
Sylvain Andresz ${ }^{1,2, *}$, Akihiro Sakoda ${ }^{1,3, *}$, Wi-Ho Ha ${ }^{1,4}$, Franz Kabrt ${ }^{1,5}$, Takahiko Kono ${ }^{1,6}$, Marina Sáez Muñoz ${ }^{1,7}$, \\ Omar Nusrat ${ }^{1,8}$, Cinthia Papp ${ }^{1,9}$, Rui Qiu ${ }^{1,10}$, Pete Bryant ${ }^{11,12}$ \\ ${ }^{1}$ The Leadership Committee of the IRPA Young Generation Network; ${ }^{2}$ Nuclear Protection Evaluation Centre, Fontenay-aux-Roses, France; ${ }^{3}$ Ningyo-toge \\ Environmental Engineering Center, Japan Atomic Energy Agency, Okayama, Japan; ${ }^{4}$ Laboratory of Health Physics, Korea Institute of Radiological and \\ Medical Sciences, Seoul, Korea; ${ }^{5}$ Division for Radiation Protection, Austrian Agency for Health and Food Safety (AGES), Vienna, Austria; ${ }^{6}$ Sector of \\ Fukushima Research and Development, Japan Atomic Energy Agency, Iwaki-shi, Japan; ${ }^{7}$ Laboratorio de Radiactividad Ambiental, Universitat Politècnica de \\ València, Valencia, Spain; ${ }^{8}$ Health Physics and Environmental Safety Research Group, Faculty of Energy Systems and Nuclear Science, Ontario Tech \\ University, Oshawa, ON, Canada; ${ }^{9}$ National Commission of Atomic Energy, Buenos Aires, Argentina; ${ }^{10}$ Department of Engineering Physics, Tsinghua \\ University, Beijing, China; ${ }^{11}$ EDF Energy, Bristol, UK; ${ }^{12}$ Department of Physics, University of Surrey, Guildford, UK
}

\section{Letter}

\section{Received March 18, 2021}

Revision April 21, 2021

Accepted May 12, 2021

\section{Corresponding author: Akihiro Sakoda}

Ningyo-toge Environmental Engineering Center, Japan Atomic Energy Agency, 1550 Kamisaibara, Kagamino-cho, Tomata-gun, Okayama 708-0698, Japan

E-mail: sakoda.akihiro@jaea.go.jp

(10) https://orcid.org/0000-0002-6270-6661

*These authors contributed equally to this work.

This paper is an invited paper recommended by the Japan Health Physics Society (JHPS).

\begin{abstract}
This is an open-access article distributed under the terms of the Creative Commons Attribution License (http://creativecommons.org/licenses/by-nc/4.0), which permits unrestricted use, distribution, and reproduction in any medium, provided the original work is properly cited.
\end{abstract}

\section{Copyright $\odot 2021$ The Korean Association for} Radiation Protection

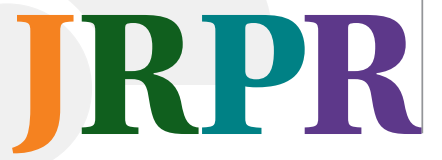

Since its establishment in 2018, the Young Generation Network (YGN) has been dedicated, with support of the International Radiation Protection Association (IRPA), to a variety of activities to promote communication, collaboration and professional development of students and young professionals in the area of radiation protection and its allied fields. This article reports our recent activities from the middle of 2018 to the beginning of 2021, with highlights on some important events: "Joint JHPS-SRP-KARP Workshop of Young Generation Network" (December 2019 in Japan); contribution to "Nuclear Energy Agency Workshop on Optimization: Rethinking the Art of Reasonable" (January 2020 in Portugal); survey on the impact of coronavirus disease 2019 (COVID-19) on radiation protection among IRPA YGN members (March 2020); and contribution to IRPA 15 ( $15^{\text {th }}$ International Congress of the IRPA; January-February 2021, online). The discussion and insight obtained from each activity are also summarized. The IRPA YGN will aim to achieve its on-going activities and continue to follow the ways paved in the Strategic Agenda and despite the challenges raised by the COVID-19 pandemic. Namely, running an international survey (for example, on the usage of social media in radiation protection, and on the long-term consequences of the COVID-19 pandemic), engaging national YGNs, extending the network, finding new relationships with networks with an interest in the young generation and participation in (remote) events will be aspired for.

Keywords: International Radiation Protection Association (IRPA), Young Generation Network (YGN), International Collaboration, Networking, Impact of COVID-19

\section{Introduction}

The Young Generation Network (YGN) was officially established as part of the International Radiation Protection Association (IRPA) in the spring of 2018 [1]. The IRPA YGN is an international network of "young professionals" across the field of radiation protection. Its primary function is to promote communication, collaboration and professional development of students and young professionals in the area of radiation protection and its allied fields. 
Table 1. Members of IRPA YGN Leadership Committee (as of January 2021)

\begin{tabular}{lll}
\hline Region & \multicolumn{1}{c}{ Country } & \multicolumn{1}{c}{ Member } \\
\hline Africa & Ghana & Francis Otoo \\
& Nigeria & Bashir S. Hussain \\
& Tunisia & Tahar Hamida \\
Americas & Canada & Omar Nusrat \\
& USA (and Ghana) & Innocent Tsorxe \\
& Argentina & Cinthia Papp \\
Asia & China & Rui Qiu \\
& India & V. P. Singh \\
& Japan & Akihiro Sakoda (Secretary) \\
& & Takahiko Kono \\
& South Korea & Wi-Ho Ha \\
Europe & Austria & Franz Kabrt \\
& Czech Republic & Anna Michaelidesova \\
& France & Sylvain Andresz (Chair) \\
& Spain & Marina Sáez Muñoz \\
& UK & Thiago Viana Miranda Lima \\
\hline
\end{tabular}

IRPA, International Radiation Protection Association; YGN, Young Generation Network.

The IRPA YGN has been driven by its Leadership Committee, which is now made of 16 members of young professionals from four regions and 15 countries (Table 1). Membership of the IRPA YGN is open to all members of YGN in national radiation protection societies (IRPA's associate societies) and, where a national YGN is not in place, to students or professionals working within the first 10 years of their career in the field of radiation protection or its allied fields. A Strategic Agenda [2] has been developed to lay out how the IRPA YGN intends to work for the following years and to ensure these actions are aligned with its vision and objectives (Refer to previous articles to see the details of the launch and relevant events [3-5]).

The IRPA YGN has successfully done a variety of activities [3-9] from after its establishment to the beginning of 2021, which are summarized in Table 2 . This article presents the following topics:

(1) Joint JHPS-SRP-KARP Workshop of Young Generation Network (December 2019 in Japan);

(2) Contribution to Nuclear Energy Agency Workshop on Optimization: Rethinking the Art of Reasonable (January 2020 in Portugal);

(3) Survey on the impact of coronavirus disease 2019 (COVID-19) on radiation protection among IRPA YGN members (March 2020);

(4) Contribution to IRPA15 ( $15^{\text {th }}$ International Congress of the IRPA; January-February 2021; online)

\section{Activity}

\section{Joint JHPS-SRP-KARP Workshop of Young Generation Network (December 2019 in Japan)}

1) Background

Based on the discussion at the IRPA YGN session in the $5^{\text {th }}$ Asian and Oceanic IRPA Regional Congress on Radiation Protection (AOCRP-5), held in May 2018 in Melbourne (Australia), the Japan Health Physics Society (JHPS) and Korean Association for Radiation Protection (KARP) started the collaboration among their young members. The first joint workshop of YGN between KARP and JHPS was held in November 2018 in Jeju, Korea [6]. Firstly, main activities and plans of each society's YGN as well as their roles and responsibilities were shared. Secondly, some research projects and their findings were presented by representatives from the two societies' YGNs. Finally, all participants discussed their future plans between the two societies, especially about collaboration of young professionals, so that they agreed to have the next joint workshop in Japan in 2019.

The JHPS and UK Society for Radiological Protection (SRP) have also started the collaboration among their young professionals as part of JHPS-SRP partnership since 2018.

The above context led the JHPS and its YGN to host the joint workshop for young professionals from JHPS, SRP, KARP and others, with support of IRPA and its YGN.

\section{2) Outline}

The joint workshop of their YGNs from the JHPS, SRP, and KARP, was held in Sendai, Japan on December 4, 2019, in conjunction with the joint annual meeting of JHPS and JRSM (Japanese Society of Radiation Safety Management). Seventy-eight attendees, including students, young, experienced and senior professionals, from 13 countries joined this workshop: Australia, Bangladesh, Cameroon, China, France, India, Indonesia, Japan, Korea, Malawi, Thailand, UK, and Vietnam (Fig. 1). On the day before the workshop, a technical tour to Fukushima Daiichi Nuclear Power Station was conducted.

The purpose of this joint JHPS-SRP-KARP Workshop of YGN was to encourage the active participation of young professionals and promote the interaction of IRPA YGN, including the three national YGNs, to help them establish mentoring in their areas of interest.

The workshop's program is outlined in Supplementary Figs. S1 and S2. In the morning session, five representatives 
Table 2. Main Activities of the IRPA YGN Done from the Middle of 2018 to the Beginning of 2021

\begin{tabular}{|c|c|c|c|}
\hline Type & Date (Place) & Activity & Remarks \\
\hline Publication & $2018-2020$ & $\begin{array}{l}\text { Contribution to international journals for } \\
\text { dissemination of the activities }\end{array}$ & Refs. [3-9]. \\
\hline \multirow[t]{4}{*}{$\begin{array}{l}\text { Presence at } \\
\text { events }\end{array}$} & $\begin{array}{r}\text { July 16-18, } 2019 \\
\text { (Taiyuan, China) }\end{array}$ & $\begin{array}{l}\text { Contribution to } 10^{\text {th }} \text { International Symposium } \\
\text { on Radiation Safety and Detection } \\
\text { Technology (ISORD-10) }\end{array}$ & $\begin{array}{l}\text { Ref. [7]. } \\
\text { The Youth Committee of China Society of Radiation Protection } \\
\text { (CSRP-YC) held the "Young Scientist Forum," which was } \\
\text { attended by more than } 70 \text { young scholars from China, Korea, } \\
\text { Japan, Vietnam, or other countries, coming from } \\
\text { universities, research institutes and companies. } \\
\text { The IRPA YGN gave words this forum to congratulate its opening } \\
\text { in the form of a recorded video and describe the missions and } \\
\text { objectives of the IRPA YGN. } \\
\text { This forum exchanged } 15 \text { academic talks, covering multiple } \\
\text { research directions of radiation safety and detection. It created } \\
\text { a positive effect in promoting exchanges and cooperation, } \\
\text { deepening friendship with world, widening our sight and } \\
\text { intensifying training and innovation in their career of young } \\
\text { radiation protection personnel in our countries. }\end{array}$ \\
\hline & $\begin{array}{l}\text { December 4, } 2019 \\
\text { (Sendai, Japan) }\end{array}$ & $\begin{array}{l}\text { Joint JHPS-SRP-KARP Workshop of Young } \\
\text { Generation Young Generation Network (YGN) }\end{array}$ & See Section 2 and Ref. [6]. \\
\hline & $\begin{array}{l}\text { January 13-15, } 2020 \\
\text { (Lisbon, Portugal) }\end{array}$ & $\begin{array}{l}\text { Contribution to Nuclear Energy Agency } \\
\text { Workshop on Optimization: Rethinking the } \\
\text { Art of Reasonable }\end{array}$ & See Section 3. \\
\hline & $\begin{array}{l}\text { January 18-February } \\
5,2021 \text { (Online) }\end{array}$ & $\begin{array}{l}15^{\text {th }} \text { International Congress of the IRPA } \\
\text { (IRPA15) }\end{array}$ & See Section 5. \\
\hline Survey & March, 2020 & $\begin{array}{l}\text { Survey on the impact of COVID-19 on radiation } \\
\text { protection among IRPA YGN members }\end{array}$ & See Section 4 \\
\hline \multirow[t]{2}{*}{ Networking } & April 2019 to present & Portraits of young professionals & $\begin{array}{l}\text { The aim is to introduce young people working in the field of } \\
\text { radiation protection. Contributions from four individuals from } \\
\text { Japan, China, UK and France have been posted on the website } \\
\text { (https://www.irpa.net/YPN/contact.asp) }\end{array}$ \\
\hline & 2020 & Identity Card Contest & $\begin{array}{l}\text { The Identity Cards can be seen in Supplementary Fig. S1. } \\
\text { In this competition, national YGNs described themselves (e.g., } \\
\text { members, activities, and perspectives) with a single A4 sheet. } \\
\text { Contributions from six national YGNs from Austria, Argentina, } \\
\text { China, France, Japan, and Spain were received. The Austrian } \\
\text { YGN won this competition, after careful consideration with } \\
\text { support of IRPA President and Executive members. }\end{array}$ \\
\hline
\end{tabular}

IRPA, International Radiation Protection Association; JHPS, Japan Health Physics Society; SRP, Society for Radiological Protection; KARP, Korean Association for Radiation Protection; COVID-19, coronavirus disease 2019.

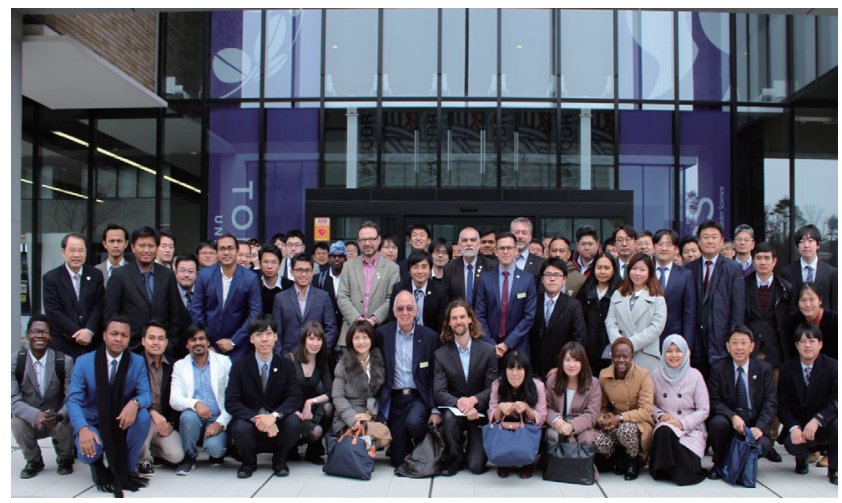

Fig. 1. Group photo taken at the Joint JHPS-SRP-KARP Workshop of Young Generation Network (December 2019 in Japan). JHPS, Japan Health Physics Society; SRP, Society for Radiological Protection; KARP, Korean Association for Radiation Protection. of national YGNs working under IRPA's associate societiesJHPS (Japan), SRP (UK), KARP (Korea), SFRP (France), and CSRP (China)—shared their activities and plans. Then, all participants discussed on the three key questions in radiation protection and its allied fields, the details of which are summarized in the next section.

In the afternoon session, 22 young professionals and students presented their research in a variety of topics such as environmental radioactivity, radiation measurement and simulation, radiation protection and regulation, radiochemical analysis, emergency monitoring, radiation application, and communication. The best presentation award went to $\mathrm{N}$. Kataoka from Japan ("Surface treatment for shell egg by low energy electron beam") [10] and E. W. Katengeza from Mala- 
wi ("A brief scrutiny of Malawi's development agenda of visà-vis status of atomic regulatory infrastructure") [11].

\section{3) Summary of the morning session discussion ("IRPA YGN} Session")

Following the presentations from the YGNs of the five radiation protection societies, a discussion session was held with the attendees to explore some of the key themes and points raised, as well as to gauge the views of the diverse range of attendees from various countries across the world.

Three key questions were explored as below.

- Is there a consistent view across countries that there is a shortage of Young Professionals and Researchers in Radiation Protection?

The views of the attendees were mixed. In the case of those working within the research and academic environment the feeling was that there was no shortage in attracting people into the radiation protection area. However, professionals across Healthcare and Nuclear were noting difficulties in not only encouraging young professionals to see radiation protection and its allied fields as a career path, but also retaining individuals.

It was emphasized that radiation protection includes both the academic researchers and the professionals who are practicing radiation protection on a daily basis and that a shortage in one area impacts the field as a whole.

- What motivated attendees to enter the field of radiation protection? What can be done to encourage others?

A strong theme expressed from the attendees was the link of radiation protection to nuclear energy production. However, it was noted that more of the attendees came from a nuclear focus than from other sectors, such as healthcare.

The general view of the audience was positive towards nuclear energy, highlighting its importance in tackling climate change, with many attendees keen to enter the field of radiation protection to help their countries develop their future nuclear programs.

It was noted that one of the main challenges of the radiation protection profession, with regards to encouraging individuals into the field, was the need to tackle the negative public perception of radiation and conflicting views presented online and by both media and social media. The need to have a positive relatable message that can be readily disseminated to the public via social media and other means of engagement was seen as key.

In addition, the general education (including the science and radiation education) of the public from a young age was seen as key to tackling the conflicting views and misconceptions around radiation, along with raising visibility of careers in radiation protection and encouraging young professionals into the field.

-What are the challenges people see in developing and retaining young researchers and professionals?

The general views of the attendees were the need to ensure young researchers and professionals feel part of the field, and have a future career path.

Attendees noted that at times the younger professionals and researchers can feel disconnected from contributing to the important work and discussions influencing the field of radiation protection.

The radiation professional societies were asked whether they encourage young professionals and researchers to contribute to their working groups and committees and foster an inclusive environment.

IRPA noted that they encourage young professionals and researchers to take part in their regular task groups and with the support of the IRPA YGN young members joined the existing Task Groups.

The UK noted it actively encourages diversity across all their committees, working groups and more recently the executive council, not only in relation to age or experience diversity, but also gender, ethnicity and technical background.

Although the benefits of young generation networks and having themed events were noted, the importance of ensuing these for not becoming a barrier was emphasized by attendees. The need to encourage an open dialogue and collaboration between the more experienced members of the radiation protection field and younger professionals and researchers was seen as key, where possible events should be run ensuring inclusivity of both.

\section{Contribution to Nuclear Energy Agency Workshop on Optimization: Rethinking the Art of Reasonable (January 2020 in Portugal)}

The Nuclear Energy Agency (NEA) held a 3-day workshop in Lisbon, Portugal to exchange experiences and identify approaches to better achieve radiation protection under the different exposure situations and how to achieve it at best given the circumstances (may it be scientific, economical, societal and ethical). The program committee was keen to include the views of the young professionals. Within the workshop young members from different background met 
and discussed the topic and on day 3 , these young professionals gathered at a plenary session to show the audience their findings.

It was decided to explore the use of innovation and cutting-edge tools for optimization of radiation protection purposes:

- Social media and other up-to-date communication tools such as TV series (Chernobyl on HBO) were brought up as it can generate public interest in radiation protection and are ways to disseminate radiation awareness content. Social media is a key challenge for communication and radiation protection professionals growing up with these media can use these tools properly for a fast and constructive communication in both ways.

- Crowdsourcing and how it can mutually beneficiate to the public and the experts were also explored: An example for crowdsourcing are navigation systems, where the optimized route is calculated based on the data of other users. Citizen science can be fertile ground in some radiation protection topics such as environmental monitoring and measurement (radon).

- Artificial intelligence and its place in radiation protection has also been discussed, notably for decision-making in complex situations. Artificial intelligence- under its different form-offered great opportunities but also brought new challenges and ethical decision.

The presented issues provided a fruitful basis for a discussion with the audience. A very interesting exchange of different views and new input for reflecting was the consequence.

\section{Survey on the Impact of COVID-19 on Radiation}

Protection among IRPA YGN Members (March 2020)

In March 2020, the IRPA YGN distributed a questionnaire about the impact of COVID-19 on radiation protection among its members. More than 30 testimonies from 10 countries were received. A large panel of topics was covered by the participants and the outcome of the survey is summarized below. The summary is also available from the website in English, Spanish, Japanese and German [1].

\section{1) General impacts}

Due to the pandemic and the national lockdowns implemented in most countries, the program of activities for the year had to be reconsidered totally and several activities were given less priority. As such, business trips were cancelled, all events gathering radiation protection professionals (meetings, seminar, and symposium) were postponed or cancelled and teleworking was implemented as a new standard of work.

2) Nuclear-cycle related industries (nuclear power plants and other installations)

This industry has been deemed as essential infrastructure and has continued operation, but with less staff on-site (rotating schedule) and with important modification of activities and workplace station (regular disinfection, minimization of contact, masks, etc.) and new specific protocol (e.g., disinfection of the detectors at the exit of controlled areas of nuclear power plants).

The quality control of the environmental monitoring system and the circulation of samples to laboratories have been suspended or limited to essential samples. Other activities that have been postponed include the calibration of instruments, other quality assurance procedures, as well as the acquisition of new equipment.

\section{3) Hospitals}

Non-essential operations have been postponed to manage and treat COVID-19 patients and emergencies. The main priority has been the biological risk and not radiation protection. On one hand, non-essential procedures such as calibration and quality control of equipment provided by manufacturers or laboratories have been postponed. On the other hand, hospitals have contacted laboratories to test urgently large amounts of radiological protection clothing (used for computed tomography imaging of lungs, hence for COVID-19 diagnosis). Specific protocols have been implemented for safe-transfer of materials, but the augmented sanitary risk has raised high concerns from the participants. Overall, the sector faced a constant balance (or transfer) of radiological versus sanitary risks.

\section{4) Regulation}

Office work has been replaced by home office work "without influencing the work" so far while on-site inspections have been postponed in general, questioning the impact and maintaining a high-level of radiation protection supervision over mid-term. Virtual inspection has been implemented with some success.

5) Education and training

This sector encountered a major switch toward a full virtu- 
al setting: face-to-face courses and training have all been cancelled or replaced by remoted teaching. Early difficulties have been encountered by teachers in order to adapt and gain experience with new tools. The lack of interaction was regretted by teachers and most students.

6) Putting COVID-19 and radiation protection in comparison

The knowledge about radiation protection has been reported as very useful in the situation because the principles for preventing radiation exposure and virus contamination are comparable-time, distance, and shielding/PPE (personal protective equipment). This has facilitated the communication of the adapted and new procedures to the workers accustomed to radiation protection. Japanese participants highlighted that the experience from the Fukushima accident has been re-used at hospitals: the triage at the entrance and the delimitation of contaminated vs. non-contaminated areas. The topic of communication in emergency situation have also been judged very similar. Hoax can spread rapidly and experts/scientists need to communicate clearly and in a harmonized and coordinated manner.

\section{7) Synthesis and lessons-learned}

The COVID-19 pandemic has affected nearly all radiation protection related sectors and the collection of IRPA YGN testimonies allowed for the viewpoint of the young generation to be shared. The impacts on radiation protection have never been negligible, and significantly strong in some sectors and types of work. Another highlight of the survey are the specific impacts encountered by the young generation. The young generation is generally highly represented in practical-based work in laboratories and research work and these areas have been judged as non-essential and activities postponed in general. The impacts for students in radiation protection are critical. The "technical agility" of the young generation certainly allows for a fast adaptation to working remotely, but the process was not smooth.

The survey was carried out during the first pandemic wave. As the pandemic and its impacts continue, the IRPA YGN now aims to engage in a reflection about the impacts of the later parts of the pandemic period for the young generation in radiation protection, to get an overview of how far specific fields could adapt to the situation. It is possible that these solutions may be useful and adapted for the post-pandemic period.

\section{Contribution to IRPA15 (January-February 2021, Online)}

As mentioned in the IRPA YGN Strategic Agenda 2018-2020 [2], the $15^{\text {th }}$ International Congress of the IRPA (IRPA15) was a milestone for the IRPA YGN, next to its establishment in the spring of 2018. IRPA15 was supposed to be held in May 2020 in Seoul (Korea), but rescheduled to January 18-February 5, 2021 due to the COVID-19 pandemic. Also, the congress format was changed to the online style. The IRPA YGN has therefore adapted its contribution in the congress and print its mark in the below activities:

- Organization in full of the special session "Innovation in Radiation Protection," with a focus on artificial intelligence and radiation protection. Table 3 indicates the session's program: four presentations (pre-recorded) and live discussion among IRPA YGN members.

- Contribution to the special session "Women in Radiation" (Live webinar). Rui Qiu made a presentation with a title of "Roles that women have played in radiation protection from the IRPA YGN leadership committee and

Table 3. Program of the Special Session "Innovation in Radiation Protection" at the IRPA15

\begin{tabular}{lll}
\hline Content/Date & Title & Speaker (affiliation) \\
\hline $\begin{array}{l}\text { Pre-recorded presentations (15 min for each)/ } \\
\text { January 18-February 5, } 2021\end{array}$ & $\begin{array}{c}\text { Current researches on application of Al for radiation } \\
\text { protection in POSTECH } \\
\text { The benefits and potential limits of Al in radiation }\end{array}$ & Song Hyun Kim (POSTECH, Korea) \\
& protection: a prospective case study & Sylvain Andresz (CEPN, France) \\
& Isotope identification using deep learning: an explanation & Mario E. Gomez (Oregon State Univ., USA) \\
& Deep learning approaches for pseudo gamma & Byoungil Jeon (KAERI, Korea) \\
& spectroscopy of a plastic scintillation detector & \\
Live session (90 min, via Zoom)/January 28, 2021 & Discussion (Co-chairs: Sylvain Andresz and Akihiro & All speakers and audiences \\
(Closed meeting only for young professionals) & Sakoda) & \\
\hline
\end{tabular}

IRPA15, the $15^{\text {th }}$ International Congress of the International Radiation Protection Association; Al, artificial intelligence; POSTECH, Pohang University of Science and Technology; CEPN, Le Centre d'étude sur l'Évaluation de la Protection dans le domaine Nucléaire [Nuclear Protection Evaluation Centre]; KAERI, Korea Atomic Energy Research Institute. 


\section{from China."}

- Contribution to the thematic session "The Future of our Radiation Protection Profession" (Geehyun Kim and Pete Bryant).

- Running of the IRPA15 Young Scientists Award (YSA) review committee (Wi-Ho Ha, Sylvain Andresz, and Akihiro Sakoda).

\section{Perspectives}

The IRPA YGN aims to achieve its on-going activities and continue to follow the ways paved in the Strategic Agenda [2] and despite the challenges raised by the COVID-19 pandemic. Running a survey, engaging national YGNs in a contest, extending the network, finding new relationships with networks with an interest in the young generation and participations in (remote) events are aspired for. Investigating the usage of social media by the young generation in radiation protection and investigating the long-term consequences of the COVID-19 pandemic are other issues that are pursued and are considered at the forthcoming revision of the Strategic Agenda.

Lastly, we would like to touch the words of panelists at the session "The Future of our Radiation Protection Profession" in IRPA15, which were answers to the following question: "What are expectations or priorities for the future of our radiation protection profession?" The answers will guide our ways forward and push our future activities—only essences of which are listed below.

- Making a good image for the radiation protection profession and provide a clear vision in the future.

- Empathy between generations.

- Bridging a gap between radiation protection professionals and communication, social media specialists, to help reaching much wider audience and creating a target of the message.

- Support for academic programs to ensure the sustainability and fostering of the young generation.

- Importance of mentoring, networking, and retaining with regards to new and young professionals.

- Emphasis for professionals focus on the development of education, training and technique approaches. One positive aspect of the COVID-19 pandemic is the larger usage of online training opportunities and communication on virtual mode.

- International cooperation and collaboration are neces- sary to guarantee sustainability, necessary skills and extensive knowledge transfer to young generation.

- We (radiation protection professionals or IRPA members) are working in a small community, each with their own promising initiatives. Increased joint efforts among these groups has great potential to improve collaboration between radiation protection professionals worldwide.

\section{Conflict of Interest}

No potential conflict of interest relevant to this article was reported.

\section{Acknowledgements}

The IRPA YGN have made the achievements with great supports from young professionals and students across the world as well as IRPA and its associate societies. Special thanks go to Dr Roger Coates OBE (immediate past President of IRPA), Dr Alfred Hefner (immediate past member of IRPA Executive Council) and Dr Hiroko Yoshida (member of IRPA Executive Council) for their warm support.

\section{Author Contribution}

Conceptualization: Andresz S, Sakoda A, Ha W, Kabrt F, Kono T, Muñoz M, Nusrat O, Papp C, Qiu R, Bryant P. Writing - original draft: Andresz S, Sakoda A, Kabrt F, Bryant P. Writing - review \& editing: Andresz S, Sakoda A, Ha W, Kabrt F, Kono T, Muñoz M, Nusrat O, Papp C, Qiu R.

\section{References}

1. IRPA Young Generation Network [Internet]. [place unknown]: International Radiation Protection Association; c2021 [cited 2021 Jun 23]. Available from: https://www.irpa.net/irpa_mini.asp? site=YPN/index.asp.

2. International Radiation Protection Association Young Generation Network (IRPA YGN): Strategic Agenda for 2018 through 2020 [Internet]. [place unknown]: International Radiation Protection Association; 2020 [cited 2021 Jun 23]. Available from: https://www.irpa.net/members/54777/\%7BC7A45B52-D6D140D3-8855-FF9FFAA5E737\%7D/IRPA\%20YGN\%20Strategic\%20Agenda\%202018-2020.pdf.

3. Andresz S, Sakoda A, Bryant P, Fernandez I, Kono T, Kim JS, et al. The IRPA Young Generation Network. European ALARA Network Newsletter 2018;41:19-21. 
4. Sakoda A, Kono T, Kataoka N, Andresz S. Establishment and activities of Young Generation Network (IRPA YGN) in International Radiation Protection Association. Jpn J Health Phys. 2019; 54(3):181-187.

5. Sakoda A, Andresz S, Bryant P. Launch of the IRPA Young Generation Network (IRPA Bulletin 18) [Internet]. [place unknown]: International Radiation Protection Association; 2018 [cited 2021 Jun 23]. Available from: https://www.irpa.net/members/54592/ \%7B07B3507E-F63F-4A15-8689-09C81C516B60\%7D/IRPA\%20 Bulletin\%2018\%20(English).pdf.

6. Sakoda A. KARP-JHPS Joint Workshop of Young Generation Network (IRPA Bulletin 20) [Internet]. [place unknown]: International Radiation Protection Association; 2018 [cited 2021 Jun 23]. Available from: https://www.irpa.net/members/54592/ \%7B9B823FC0-6B6F-49A7-A4C9-1C018BD0D37D\%7D/IRPA\% 20Bulletin\%2020\%20(English).pdf.

7. Qiu R. The Young Scientist Forum at the ISORD-10 (IRPA Bulletin 23) [Internet]. [place unknown]: International Radiation Protection Association; 2019 [cited 2021 Jun 23]. Available from: https://www.irpa.net/members/54592/\%7B488F2C7E-950D-
4D14-A76D-9303A4248F4B\%7D/IRPA\%20Bulletin\%2023\%20 (English).pdf.

8. Sakoda A, Hirota S, Kono T, Kataoka N. Joint JHPS-SRP-KARP Workshop of Young Generation Network (IRPA Bulletin 24) [Internet]. [place unknown]: International Radiation Protection Association; 2019 [cited 2021 Jun 23]. Available from: https:// www.irpa.net/members/54592/\%7B60984EAC-3CF6-40CE9815-F802D1ACF721\%7D/IRPA\%20Bulletin\%2024.pdf.

9. Andresz S, Sakoda A, Kabrt F. The IRPA Young Generation Network (IRPA YGN): where are we now? (IRPA Bulletin 24) [Internet]. [place unknown]: International Radiation Protection Association; 2020 [cited 2021 Jun 23]. Available from: https://www. irpa.net/members/54592/\%7B7984120C-1847-4B09-8044-6345422853BB\%7D/IRPA\%20Bulletin\%2025\%20(English).pdf.

10. Kataoka N, Kawahara D, Sekiguchi M. Surface treatment of eggshells with low-energy electron beam. J Radiat Prot Res. 2021; 46(1):8-13.

11. Katengeza EW. A brief scrutiny of Malawi's policy on nuclear power. J Radiat Prot Res. 2020;45(4):147-153. 